\title{
Capitalization of Public Goods and Its Distribution Effect: Empirical Evidences and Policy Implications in China
}

\author{
Yuanfeng Liu (Corresponding author) \\ Center for Social Security Studies, Wuhan University \\ Luojia Hill, Wuhan 430072, China \\ Tel: +86-027-6875-5887Ｅ-mail: haitianxxing@sohu.com \\ Shenbo Yi \\ College of Law and Humanities, Nanchang Hangkong University \\ 696 South Fenghe Revenue, Nanchang 330063, China \\ Tel: +86-791-386-3625Ｅ-mail: yishenbo@126.com
}

Received: November 29, 2010 Accepted: January 5, 2011 doi:10.5430/ijba.v2n1p38

\begin{abstract}
Capitalization of public goods refers to the economic phenomenon that some assets absorb the cost of public goods and the prices of assets rise consequently. It results in an interpersonal and interregional income distribution effect. The distribution effect from capitalization of public goods illuminates that it is reasonable to levy property tax and provide more public goods in rural areas.
\end{abstract}

Keywords: Public goods, Capitalization, Distribution effect, Revenue bonus

There is a close relation between income distribution and financial revenue and expenditure, and a variety of literature has been published on this issue. In China, relevant studies are focused on the influence of tax, especially individual income tax, on income distribution. In respect of financial expenditure, emphasis is placed on the impact of transfer expenditures, especially social security expenditures, on income distribution. However, there is no literature dedicated to the influence of purchase expenditures, including public goods supply, on income distribution. In western developed countries, relevant topics relating to the influence of public goods supply on income distribution have been discussed relatively earlier. Wolfgang Buchholz and Wolfgang Peters (2008) designed a selection mechanism satisfying the benefit principle, the ability-to-pay principle and the equality principle of taxation, thus realizing the effective burden sharing of public goods and keeping the income neutrality during financing for public goods. Geoffrey Brennan and Michael Brooks (2007) discussed the optimality in public goods supply. They argued that the respect to social rules would affect the voluntary supply of public goods, thus making the public goods supply deviate from the optimal level based on evaluation of utility. Henry Aaron and Martin McGuire (1970) analyzed the relation between public goods and income distribution: due to different income levels and consumption patterns, people evaluate the utility of public goods differently; therefore, public goods have an income distribution effect. When a person receives utility from public goods greater than the contribution he makes, it implies he has received consumption subsidy; when a person receives utility less than his contribution, it implies he has paid additional tax. This distribution effect can be balanced at the optimal level of public goods supply, that is, consumption subsidies equal to additional taxes. Excessive supply of public goods results in negative net distribution effect, while inadequate supply leads to positive net distribution effect. Geoffrey Brennan (1967) disclosed the distributional implications of public goods. He argued that the distribution effect of public goods originated from people's different evaluations of the utility of public goods. Not only there are information obstacles for evaluating the distribution effect of public goods, but people will adjust their consumption patterns according to tax structure and public goods supply; hence, the income neutrality of effective public goods supply cannot be realized even through Lindahl pricing. Wallace E. Oates (1969), according to empirical data of US, discussed the impact of public spending and tax capitalization on property values, especially values of real property, towards two different directions respectively: the former increases property values, while the latter decreases. He tested tax capitalization and the Tiebout hypothesis. The empirical data showed that property taxes did not increase with public spending and the influence of public spending on property values could not be offset by tax capitalization, but rational consumers would trade off benefits of public spending and tax burden. Anwar M Chaudry-Shah (1989) used a 
capitalization approach to analyze the fiscal incidence at the local level. The empirical data of a jurisdiction in Canada suggested that tax burden and family income had a positive correlation, but with the increase of income the correlation declined and the poor was more benefited from financial expenditure. Seen from the income distribution effect of the whole local public sector, there existed income redistribution from the middle class to the poor and the rich, and the local public sector aggravated income inequality though its incidence was limited. John Yinger (1982) provided a review of capitalization and the theory of local public finance: the precondition for local financial variables entering housing prices through capitalization is that there are free immigrants bidding for the houses; hereby the capitalization of financial variables would affect the city structure, and according to the Tiebout model, cities will be districted according to income and taste. Since citizens can determine the level of public services and the tax rates by vote, capitalization will not result in simplex community. Since the efficiency of public expenditure is determined by vote to a great extent, different jurisdictions will witness different public service levels and efficiencies.

As cited above, the means and approaches of capitalization of public goods have been widely discussed abroad and there are a lot of empirical studies of the distribution effect of public goods; however, the theoretical analysis of foreign literature on the distribution effect of public goods is focused on different utility evaluation of public goods made by the residents as consumers, and the capitalization of public goods is based on the precondition that immigrants bid for houses and make choices among a variety of public service packages and tax burdens. Once houses become investment goods, the divide between residents and immigrants has not significance any longer, and bidding for houses does not mean choices of public service packages - tax burdens any more. The distribution effect of public goods arises not only from the utility differences of public goods to different residents, but also from the different influences of public goods on property values. Practically, the political, economic and social systems, especially financial and taxation, of US and other western countries quite differ from those of China, and so the conclusions of western empirical studies do not apply to China. Due to the residence permit system and other institutional factors, immigrant workers, who entered cities from rural areas in the tide of urbanization, cannot enjoy the public services as much as the original residents do though they also work and live in the cities. Hence, to choose housing in a Chinese city does not means choosing a public service package, and the houses in China have a visible character as investment goods. This paper, starting from the public goods supply mechanism of China, attempts to discuss the means and approaches of capitalization of public goods in China, primarily explore the influence of public goods on the prices of houses and other properties, and analyze the certain distribution effect produced by public goods through capitalization.

\section{Public goods supply and capitalization of public goods in China}

Since the tax sharing reform in 1994, a decentralized multi-level financial system has been formed gradually in China. There is a considerably explicit division of authority and responsibility between the central and the local governments in financial revenue and expenditure, and local public goods are usually provided by local governments. Owing to the uneven regional development, the symmetry of financial resources and duties and responsiblities can not been completely realized between the central and the local governments, and among the local governments of different levels. Under the current regime, this problem is mainly embodied in the revenue inadequacy of local governments, particularly governments of the county level or below. Hence, the central government provides some financial support for local governments supplying public goods, which is the most evident in Central and Western China. Similar support is also provided by local governments of upper levels to those of lower levels. Meanwhile, China is actively exploring the application of the market mechanism in public goods supply and the introduction of non-government funds into public goods supply through franchising and "user pays". In rural areas, besides the public goods supply by charity foundations, donations are also mobilized to collect funds for public goods. In sum, a public goods supply mechanism with diverse financial sources based on the revenue of the concerned local government, supported by the central and upper-level governments and with participation of non-government funds and charity foundations, has been formed in China. Under such a public goods supply mechanism, the local governments do not need to secure a rigid balance of their own budgets thanks to the transfer payment from the central or upper-level government, and the deficit arising from public goods supply is backed by the central or upper-level government; hence, rigid budget constraint does not exist in public goods supply at least at the local level. The market mechanism has been introduced into the supply of a part of public goods, and even the "user pays" principle has been adopted to collect funds for a few public goods such as highways and bridges; nevertheless, the operating period of such goods does not match the return of investment, the relation between benefit and payment cannot be defined explicitly, and the social benefits arising from the use of public goods cannot be reflected through the market mechanism. Essentially, not all the funds for public goods supply can be collected according to the benefit principle. To promote the adjustment of industrial structure and the coordinated development of regional economies in China, the central government has set forth certain norms and guidance for local economic development, and the public goods supply by local governments is constrained by national economic planning and 
policies of the central government. In brief, the public goods supply in China is characterized by the following three features: first, the supply of local public goods lacks of rigid budget constraint; second, not all the funds required for public goods supply can be collected according to the benefit principle; and third, the supply of local public goods is constrained by national economic planning and policies of the central government. Based on the first characteristics, the benefits from and burdens for public goods supply, as a part of public spending, do not match each other among regions; based on the second, they do not match each other among individuals; and based on the third, the central government has the responsibility and ability to adjust the uneven distribution of benefits and burdens in public goods. The burdens for public goods supply are mainly embodied in taxes, while the benefits from public goods, except the proportion that is directly reflected in the consumer's utility function through their use or consumption, can be represented by the value increment of capital products. This is what the term "capitalization" means in economics. Where the tax burdens do not match the asset gains arising from public goods, a distribution effect is inevitably caused. In western developed countries, capitalization has become an important perspective and approach for analysis of financial policy effects.

The so-called capitalization refers to such a phenomenon: taxes, public spending and actual expenditures of other economic organizations or individuals are absorbed into relevant assets, and the asset values increase accordingly. Complete absorption of expenditures results in complete capitalization, while partial absorption results in partial capitalization. The so-called capitalization of public goods is the economic phenomenon that the actual costs of public goods are completely or partially absorbed into relevant assets, thus raising the asset prices up. The degrees and means of capitalization differ to some degree in different economic regimes and different public goods supply systems. An empirical study made by Anwar M. Chaudry-Shah (1989) showed that in a city in Canada, the taxes were completely capitalized while public expenditures partially. But there has not yet relevant theoretical or empirical studies in China. Capitalization of public goods, on the one hand, requires the existence of some assets absorbing the costs of public goods; and on the other hand, the change of asset prices can be effectively reflected in the market. Pure public goods are characterized by non-rivalness and non-excludability, but their benefits are usually confined in certain regions because people are restricted by actual conditions such as living cost, dwelling address and working places. In a fiscal jurisdiction, people share public goods quite equally though they get different utilities from these goods. If the actual constraints for migrating into this region do not exist, then public goods have complete non-excludability. As a matter of fact, people's choices of living and working in a fiscal jurisdiction are not only limited by the residence permit system, but also constrained by the labor and housing markets. Let's put aside the residence permit system and the problem of employment, but just discuss the housing market here. Since the housing market objectively functions as a mechanism selecting people who enter a fiscal jurisdiction, the sharers of public goods in this region are selected through the market. Therefore, the quantity and quality of public goods within a fiscal jurisdiction will become important criteria for people's housing choices and partially decide the prices and rents of houses, making houses become important assets absorbing the costs of public goods. Since the housing market reform in 1994, the prices and rents of houses now are primarily decided by the market. Facing the accelerated rising of house prices, the Chinese government has paid much attention to the housing market and taken relevant measures to inhibit the housing prices. However, the government has not and can not directly intervene in the housing prices, but just indirectly influence it through macro-control measures like loan and land supply. In China, the prices and rents of houses can be effectively reflected in the market, and so houses become important assets that can absorb the costs of public goods. The existence of housing market has actualized capitalization of public goods in China. From similar reasoning we can know that in addition to the housing market, commercial real property and some service products also can absorb the costs of public goods and reflect them in the market prices, thus further facilitating the capitalization of public goods. This paper theoretically analyzes the distribution effect of capitalization of public goods by containing a part of or all of their costs into the prices and rents of houses. It is difficult to acquire true data due to the imperfect market mechanism in China; hereby the size of this effect is not discussed but its objective existence confirmed with empirical evidences and its policy implications disclosed in this paper.

\section{The distribution effect of capitalization of public goods}

In a jurisdiction, public goods are shared by all the people. Suppose the effective supply of public goods is realized, then according to the characteristics of public goods there is $\Sigma M R S_{G X}=M C_{G}$; that is, the sum of individuals' marginal rates of substitution of public goods for private goods equals to the marginal cost of public goods. Neglecting the utility differences of public goods among individuals, a unified price of public goods can be determined as $P^{*}=M C_{G} / n=E_{G} / n$. Where $n$ denotes the population, and $E_{G}$ denotes the actual expenditure on public goods. This price is not a criterion for collecting funds for public goods but a shadow price of public goods, which describes the personal worth of public goods from the angle of parity income; that is to say, under a given level of income, the payment made by an individual for the public goods does not change the total utility. According to the analysis of capitalization of public goods in the 
preceding section, the authors defines the possession of long-term residence right as the precondition for sharing public goods; hence purchase or renting of houses is equivalent to purchase of corresponding public goods, while selling or renting out houses means selling the corresponding public goods. If the immigrant population $m$ does not change the benefits received by the original population from public goods, the increment of total asset values arising from public goods supply is $m P^{*}$, which will be distributed among the sellers and lessors. Suppose the living space per capita in this region is $S$, those who possesses a living space greater than $S$ may be deemed as house sellers or lessors, then the houses to be leased or sold by an individual is $\left(S^{i}-S\right)$, where $S^{i}$ denotes the living space of individual $i$. Suppose the average living space possessed by lessees is $S$ too, then the asset income acquired by house sellers or lessors is

$$
V^{\mathrm{i}}=\frac{S^{i}-S}{S} P^{*}=\frac{S^{i}-S}{S} \bullet \frac{E_{G}}{n} \quad\left(\mathrm{~S}^{i} \geq S\right)
$$

From equation (1) we can draw the following conclusions: the greater $E_{G}$, the greater asset income acquired by house sellers or lessors; hence the more expenditures on public goods, the greater distribution effect caused by capitalization of public goods; the greater $\left(S^{i}-S\right)$, the greater asset income; hence the greater differences in residential conditions among individuals, the greater distribution effect caused by capitalization of public goods. In case of $\left(S^{i}-S\right)<0$, equation (1) is still tenable but $V^{i}$ is negative and individuals no longer get asset incomes; contrarily they will pay more for capitalization of public goods due to unequal asset distribution. The implied precondition is that an individual must rent or buy houses to reach the average level of living space, and the house value increment caused by capitalization of public goods makes him pay more to reach the average residential condition.

The distribution effect presented by equation (1) is based on the existing residential pattern and housing distribution, where $m$ is a constant and the total asset value increment is $m P^{*}$, i.e., $\Sigma V^{i}=m P^{*}$. In economic development, the population density of a jurisdiction is increasing, and $m$ becomes an endogenous variable if factors of land consolidation and real property development are introduced. Suppose a real property development project accommodates new immigrants without changing the living space per capita, then the improvement of population capacity arising from real property development can be embodied in the increase of overall housing areas, i.e., $\Delta m=f(\Delta \mathrm{S})=\Delta S / S$, where $\Delta m$ represents the increase of population absorbed, and $\Delta \mathrm{S}$ represents the increase of housing areas. As analyzed above, the purchase or renting of a house contains the purchase of public goods, hence the asset value increment arising from real property development through capitalization of public goods is

$$
H=\Delta m P^{*}=\frac{\Delta S}{S} \bullet \frac{E_{G}}{n}
$$

From equation (2) we can know that the greater $\Delta S$, which means greater scale of real property development, the more benefit acquired by real property development from capitalization of public goods; the greater $E_{G}$, which means more expenditures on public goods, the more benefit acquired by real property development from capitalization of public goods.

The distribution effect arising from capitalization of public goods is constrained by the actual financial system. If a real property gains tax is levied, a proportion of the asset value increment received by residents and real property developers through capitalization of public goods will be transferred to the government through taxation. Suppose the rate of estate value increment tax is $t$, the revenue bonus obtained by the government due to public goods supply is

$$
F=\left(\sum V^{i}+H\right) t=(m+\Delta m) P^{*} t=\frac{(m+\Delta m) E_{G}}{n} t
$$

If living space enters the resident's utility function during capitalization of public goods, i.e., there exists the implied precondition for the tenability of equation (1) in case of $\left(S^{i}-S\right)<0$, then the residents whose living spaces are smaller than the average level will pay additional expenses to reach the average level, and their asset incomes are negative. As the transfer payment for negative income tax at the same rate is intrinsically included in the asset value increment tax, from $\Sigma\left(S^{i}-S\right)=0$ we can know that the revenue bonus received by the government from that part of $\left(\Sigma V^{i}\right)$ t is zero. Therefore, it is only when living space does not enter the resident's utility function during capitalization of public goods (condition $a$ ) or when there is not such a transfer payment system (condition $b$ ) that equation (3) will be tenable. It must be mentioned, the meaning of condition $a$ differs from that of condition $b$. Under the former condition, capitalization of public goods results in a pure effect of asset value increment if the factor of real property development is neglected; while under the latter, an income redistribution effect, which means transfer payment from those who do not reach the average level of living space to those who exceed, is generated without considering the factor of real property development. Capitalization of public goods and its distribution effect suggest that it is hard to realize income neutrality 
not only in taxation but also in public expenditure. Under the unified financial system of a country, financial revenue is a basic sign indicating the economic development level of a region and the higher economic development level, the more revenue. Since capitalization of public goods can generate revenue bonus, the more sufficiently public goods are supplied in a region, the stronger ability it has to go on supplying public goods and hence further advance the regional economic development there. This will result in the Matthew effect in regional economic development, and the interregional income gap will be larger and larger without the intervention from the central or upper-level government.

\section{Empirical evidences and policy implications in China}

In China, it is not hard to find empirical evidences signaling capitalization of public goods and its distribution effect: under the planned economy system, a part of urban residents got free houses through non-market allocation. In not a few regions, considerable wealth gap exists between original and new residents even they have the same working income. In cities like Shenzhen and Dongguan, some original residents receive high incomes from house rent. Investments on public infrastructure such as metros and parks usually raise the prices of real properties around; in downtown areas with developed infrastructure and suburb areas with underdeveloped infrastructure, lands are sold through bidding at completely different prices. Generally, the greater quantity and the higher quality of public goods in a region, the higher house prices; the prices of real property in cities like Shanghai, Shenzhen and Beijing are much higher than those in western cities like Xi'an and Lanzhou. In some rural areas, houses worth almost nothing because of inadequate public goods supply, and must be sold in bundling with land operation rights to merely take back the construction cost. These economic phenomena in China show that expenditures on public goods can not only enter housing prices through capitalization, but also produce corresponding income distribution effect.

To supply public goods and increase residents' wealth is a necessary function of the government. However, the distribution effect arising from capitalization of public goods will aggravate the inequality of income distribution. Those who possess greater living spaces and more houses can acquire asset value increment through capitalization of public goods. The greater living space a person possesses and the more spent on public goods, the greater asset value increment he receives. As the income gap has been considerably big and there have been huge bubbles in the real property market in China, efforts must be made to control the expansion of income gap arising from unequal distribution of real properties. The real property tax has been levied in China since 1986, but all the real properties owned by individuals for non-business purposes are exempted from this tax. It is necessary to include housing into the scope of this tax, on the one hand, to transfer a part of the asset value increment arising from capitalization of public goods into the government revenue that is to be used for public benefits, so as to diminish the distribution effect of capitalization of public goods; and on the other hand, to inhibit speculation in the real property market, reduce the vacancy of houses, and optimize the allocation of resources. Meanwhile, the real property tax, along with the individual income tax, can help prevent high-income groups from buying houses for the purpose of tax evasion.

Capitalization of public goods and its distribution effect also inspire us with a possible solution for collecting funds for public goods. Thanks to capitalization of public goods, the values of some assets will increase because of public goods supply. Therefore, public goods are not only consumables but also investment goods. If regarded as consumables, the most effective way is to collect funds from all the consumers through Lindahl pricing. Though Lindahl pricing cannot be brought into full play because it is difficult to reveal consumer preferences, the implied idea that every one benefited from public goods must pay for them is usually carried through in practice. As investment goods, it is reasonable to collect funds according to the conditions of asset value increment. As long as $[(\mathrm{m}+\Delta \mathrm{m}) \mathrm{t}] / \mathrm{n} \geq 1$, we can collect all the funds from those who are benefited from asset value increment. To treat public goods as investment goods, some deficit of the government will be allowable because the deficit is expected to be balanced by the revenue bonus received from public goods supply.

With the process of urbanization, more and more rural residents have moved into cities and the decline of resident population has been witnessed in not a few rural areas, i.e., $(m+\Delta m) / n<0$. If the expansion of living space cannot increase the utility of rural residents, it means devaluation of rural assets, which implies the decline of tax base. It is hard to obtain revenue bonus from public goods supply in rural areas, and the decline of population will result in the increase of $E_{G} / n$, i.e., the increase of public goods burdens on rural residents. Therefore, in the context of urbanization, the public goods supply would inevitably be inadequate in rural areas without transfer payment from upper-level government. Before the completion of urbanization in China, a greater proportion of the public spending must be used to provide more public goods in rural areas.

According to the characteristics of public goods supply in China, there are a lot of institutional conveniences facilitating the central government's providing funds for local public goods. Since capitalization of public goods generates an income distribution effect among individuals and regions, to provide more public goods for underdeveloped regions and 
low-income groups is an important measure for shortening income gaps. By doing so, the side effects of direct transfer payment in some welfare states, such as stigmatization and raising the sluggard, are avoided. China should utilize its institutional advantages to shorten the income gap primarily through public goods supply.

\section{References}

Aaron, H., and McGuire, M. (1970). Public Goods and Income Distribution. Econometrica, 38, 907-920. doi:10.2307/1909699, http://dx.doi.org/10.2307/1909699

Brennan, G. (1967). The Distributional Implications of Public Goods. Econometrica, 44, 391-399. doi:10.2307/1912734, http://dx.doi.org/10.2307/1912734

Brennan, G., and Brooks, M. (2007). Esteem-based Contributions and Optimality in Public Goods Supply. Public Choice, 130, 457-470. doi:10.1007/s11127-006-9098-9, http://dx.doi.org/10.1007/s11127-006-9098-9

Buchholz, W., and Peters, W. (2008). Equal Sacrifice and Fair Burden-Sharing in a Public Goods Economy.

International Tax and Public Finance, 15, 415-429. doi:10.1007/s10797-008-9073-0, http://dx.doi.org/10.1007/s10797-008-9073-0

Chaudry-Shah, A. M. (1989). A Capitalization Approach to Fiscal Incidence at the Local Level. Land Economics, 65, 359-375. doi:10.2307/3146804, http://dx.doi.org/10.2307/3146804

Oates, W. E. (1969). The Effects of Property Taxes and Local Public Spending on Property Values: An Empirical Study of Tax Capitalization and the Tiebout Hypothesis. The Journal of Political Economy, 77, 957-971. doi:10.1086/259584, http://dx.doi.org/10.1086/259584

Yinger, J. (1982). Capitalization and the Theory of Local Public Finance. The Journal of Political Economy, 90, 917-943. doi:10.1086/261101, http://dx.doi.org/10.1086/261101 